\title{
O Escuro no Teatro: da violência à ecosofia
}

\author{
Le Noir au théâtre : \\ de la violence à l'écosophie
}

\section{Darkness in the Theatre: From Violence to Ecosophy}

Véronique Perruchon

Tradução: José Ronaldo Faleiro ${ }^{2}$ 


\section{Resumo}

Este artigo aborda a dimensão mais profunda do escuro em cena. $O$ trabalho se propõe a responder à questão subjacente ao tema, qual seja, como falar do escuro em sua dimensão mais profunda? Para tanto a sua escrita se pauta em espetáculos de renome internacional criados na França.

Palavras-chaves: Escuro da cena; luz do espetáculo; criadores de iluminação

\section{Resumo}

Cet article porte sur la dimension profonde du noir au théâtre. Ce travail propose de répondre à la question sousjacente au thème : comment parler de l'obscurité dans sa dimension la plus profonde ? Pour ce faire, le texte s'appuie sur des spectacles créés en France et de renommée internationale.

Mots-clés: Noir au théâtre ; lumière du spectacle; créateurs lumière

\section{Abstract}

This article deals with the deeper dimension of darkness on stage. The text proposes to answer the underlying question: how to talk about darkness in the theatre, in its deepest dimension? In order to do so, this article is based on performances of international reputation created in France.

Keywords: Darkness in the theatre; stage lighting; lighting designers

E-ISSN: 2358.6958

\footnotetext{
1 Véronique Perruchon, Professora em Artes da Cena na Universidade de Lille e membro do Centre d’Études des Arts contemporains [Centro de Estudos das Artes Contemporâneas], dirige um programa de pesquisa sobre a "Lumière de Spectacle" [Luz Cênica]. Depois de iniciar a sua carreira profissional como iluminadora e diretora de cena, em seu trabalho de pesquisa ela se interessou pelo campo espetacular do teatro e pela encenação. Publicou nas Presses universitaires du Septentrion as obras intituladas Noir. Lumière et théâtralité [Escuro. Luz e Teatralidade], em 2016, e André Engel. OEuvre théâtrale [André Engel. Obra Teatral], em 2018. Referências institucionais: LdS Programme de recherche "Lumière de Spectacle" [Luz Cênica]. Université de Lille. EA 3587 - CEAC - Centre d’Étude des Arts Contemporains. 59000 Lille, France.

2_José Ronaldo Faleiro, Doutor em Arts du Spectacle pela Universidade de Paris X - Nanterre. Professor pesquisador no Centro de Artes da Universidade do Estado de Santa Catarina. jifalei@gmail.com
} 
Para este número da revista Urdimento dedicado à luz, parece-me importante falar do escuro, abordando-o em sua dimensão mais profunda e por isso mesmo confrontar-nos com o que ele possui de mais desconcertante ou envolvente. No entanto, eu não gostaria de nos desviar da luz de espetáculo glosando as dimensões filosóficas e psicológicas do escuro por meio das interpretações simbólicas. Abordá- lo segundo esse método nos levaria diretamente à intelecção. Ora, como não basta pensar para ser, conforme a proclamação de Descartes, mas viver, vivamos a experiência do escuro para pensá-lo melhor. Assim, eu me proponho a responder à questão subjacente ao tema - como falar do escuro em sua dimensão mais profunda? - com base na experiência. Na dos performadores (atores, dançarinos, intérpretes, etc.), na dos espectadores e na dos criadores (coreógrafos, encenadores, iluminadores). Para tanto, farei referência a espetáculos geralmente criados na França, mas de renome internacional ${ }^{3}$. Veremos por meio destas considerações como o escuro bruto pode se deixar cativar ${ }^{4}$ e gerar atmosferas, emoções e pensamentos divergentes.

\title{
Da onipotência luminosa...
}

A luz do espetáculo seguiu histórica e contextualmente uma corrida para a potência. Da conquista da luz sobre o escuro, nos séculos XVI e XVII - tendo como ponto de referência as festas em Versalhes, em 1664 e 1668, do apropriadamente chamado de Rei Sol, que ofereceu um deslumbramento real e simbólico aos seus cortesãos - até as multiplicações de material para iluminar um espetáculo, desde a eletrificação dos teatros no século XX, a história da iluminação nos mostra essa bus$c a^{5}$. Citarei aqui apenas o texto de Louis Jouvet que descrevia, em 1937, essa subida em potência das luzes de espetáculo de maneira comparativa:

\begin{abstract}
Se analisarmos o instrumento de iluminação que é a ribalta, podemos, segundo as gravuras da época, determinar mais ou menos o número dos seus elementos: uma ribalta de trinta lamparinas já devia ser um luxo; a vela não traz grande progresso em relação à lamparina (9 velas equivalem a 10 lamparinas); mas o quinqué já vale 6 velas de cera; a lâmpada Carcel que a sucede (e que servirá mais tarde de padrão para determinar a vela decimal) tem uma potência igual a 9 velas decimais; depois vem o bico borboleta, que dá 15 velas, e, por fim, o bico Auer, 120 velas. [...]. Hoje, a ribalta da Comédie Française comporta quarenta e oito refletores, munido cada um de uma lâmpada de 150 watts, quer dizer de 3200 velas, ou seja, um total de 14.400 velas decimais ${ }^{6}$.
\end{abstract}

Os criadores de iluminação que trabalham com um espetáculo ao longo do tempo puderam também medir esse aumento dos níveis, especialmente em caso de

\footnotetext{
3 Os links de referências digitais provenientes de captações de vídeo ajudarão a ter uma ideia deles.

4 Aqui "apprivoiser" e "apprivoisement" são traduzidos como "cativar" e "cativamento", segundo a lição de Dom Marcos Barbosa em sua tradução de O Pequeno Príncipe, de Antoine de Saint-Exupéry (“Cativar é criar laços"). Um "escuro cativado" é um escuro "amansado", "adestrado", e não violentamente "domado", não violentamente "domesticado". (N. T.)

5 Não me deterei aqui no tema, cujos detalhes serão encontrados no primeiro capítulo — "Entre Luxe et lux: naissance du noir" [Entre Luxo e lux: nascimento do escuro] — do meu livro Noir, Lumière et théâtralité [Escuro, Luz e Teatralidade]. Villeneuve d'Asq: Presses universitaires du Septentrion, 2016.

6 Louis Jouvet. In: "L'homme, l'électricité, la vie" [O Homem, a Eletricidade, a Vida], Revue des Arts et métiers graphiques [Revista das Artes e Ofícios Gráficos], número especial, 1937.
} 
retomada de espetáculos criados uma dezena de anos antes, o que geralmente ocorre na ópera. É o caso do criador de luz Christophe Forey ${ }^{7}$, que analisa essa evolução referindo-se a suas experiências, sobretudo Hamlet, de Amboise Thomas, cuja luz ele criou, para a encenação de Moshe Leiser \& Patrice Caurier, primeiramente em Genebra, em 1996, depois no Covent Garden e em Barcelona, em 2001, e, por fim, no MET, em Nova York, em 2011․ Presente em todas essas reprises, diz ter ficado surpreso com os níveis originais particularmente baixos, por ele criados, quando quis reutilizá-los por ocasião da primeira reprise em Londres. Ao mesmo tempo que respeitava a criação original, teve de se adaptar à evolução da visão dos espectadores e à dimensão dos teatros, principalmente no MET, em que o palco e especialmente a platéia são bem maiores: a intensidade luminosa decresce ao quadrado da distância - portanto, muito mais rapidamente do que a distância, o que interfere na visão dos espectadores situados ao longe. Nesse caso, Christophe Forey teve de fazer com que a luz evoluísse aumentando-a, ao mesmo tempo que respeitava o espírito da criação original. Em outros casos, ficou surpreso com as iniciativas do pessoal dos teatros que acolhiam o espetáculo, e já não reconhecia as luzes criadas por ele, cujas intenções dramatúrgicas eram alteradas pela necessidade do aumento de potência do nível das luzes. Pode ser citado também o exemplo das muitas reprises de Le Nozze di Figaro de Strehler, criadas em ambiências sublimes de claro-escuro e que pouco a pouco foram sendo excessivamente iluminadas, a tal ponto que Strehler mandou retirar o seu nome da produção. As fotos de duas épocas são explícitas por si sós:

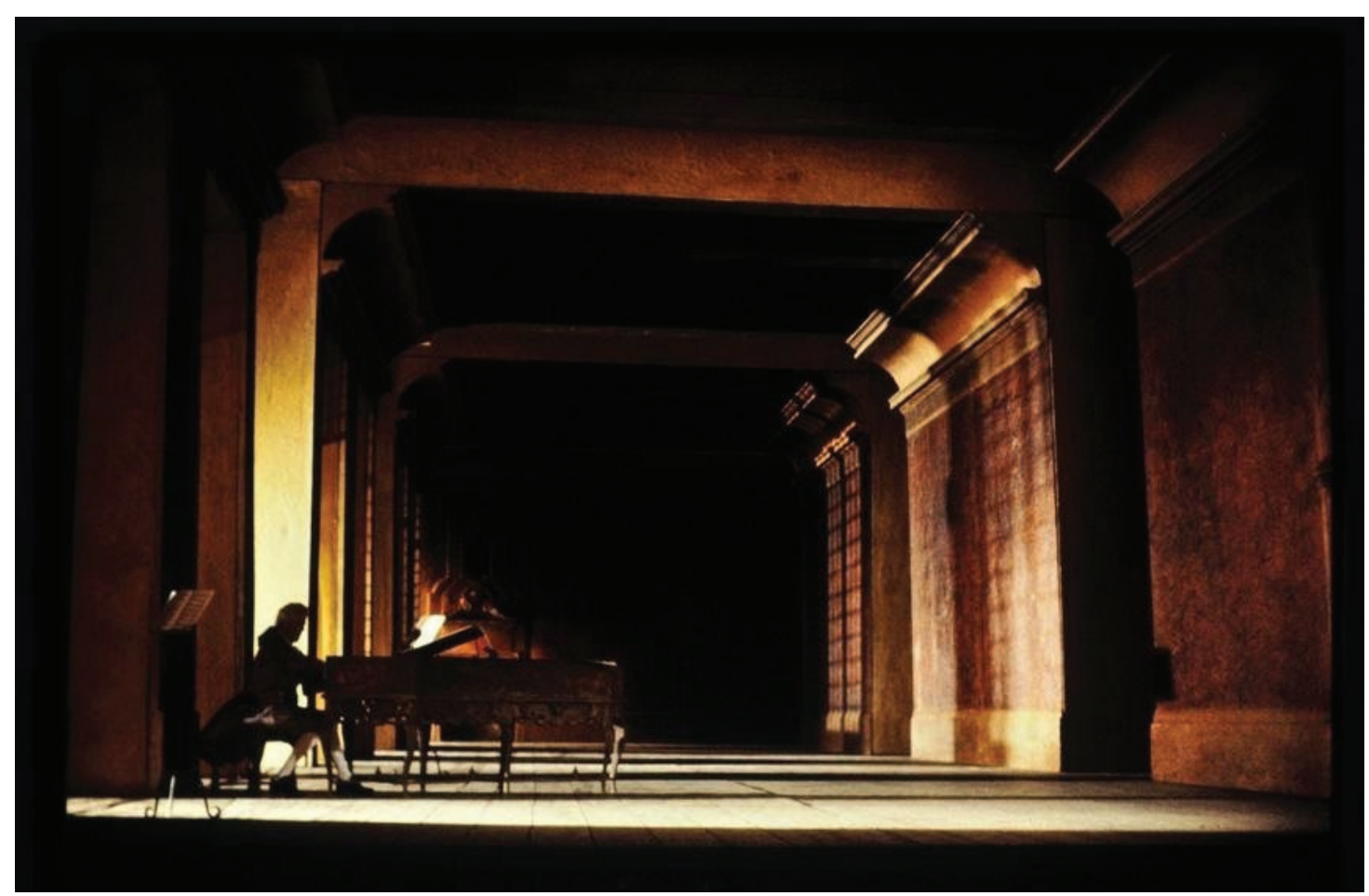

Les noces de Figaro [As Bodas de Fígaro], W. A. Mozart, direção de G. Strehler. Ato 3, foto de Daniel Cande, 1980. (C) Bibliothèque Nationale de France.

\footnotetext{
7 Criador de luz de nacionalidade francesa, Christophe Forey trabalha internacionalmente para a ópera, para dança e para o teatro, principalmente com os encenadores Moshe Leiser \& Patrice Caurier, com a coreógrafa Lucinda Childs. Cf. http://www.christopheforey.org/lumiere/spectacles.html

8 Depoimento colhido durante a preparação da mesa redonda organizada por Antonio Palermo para o colóquio Tosc@Paris, 27-29 de junho de 2019.
} 


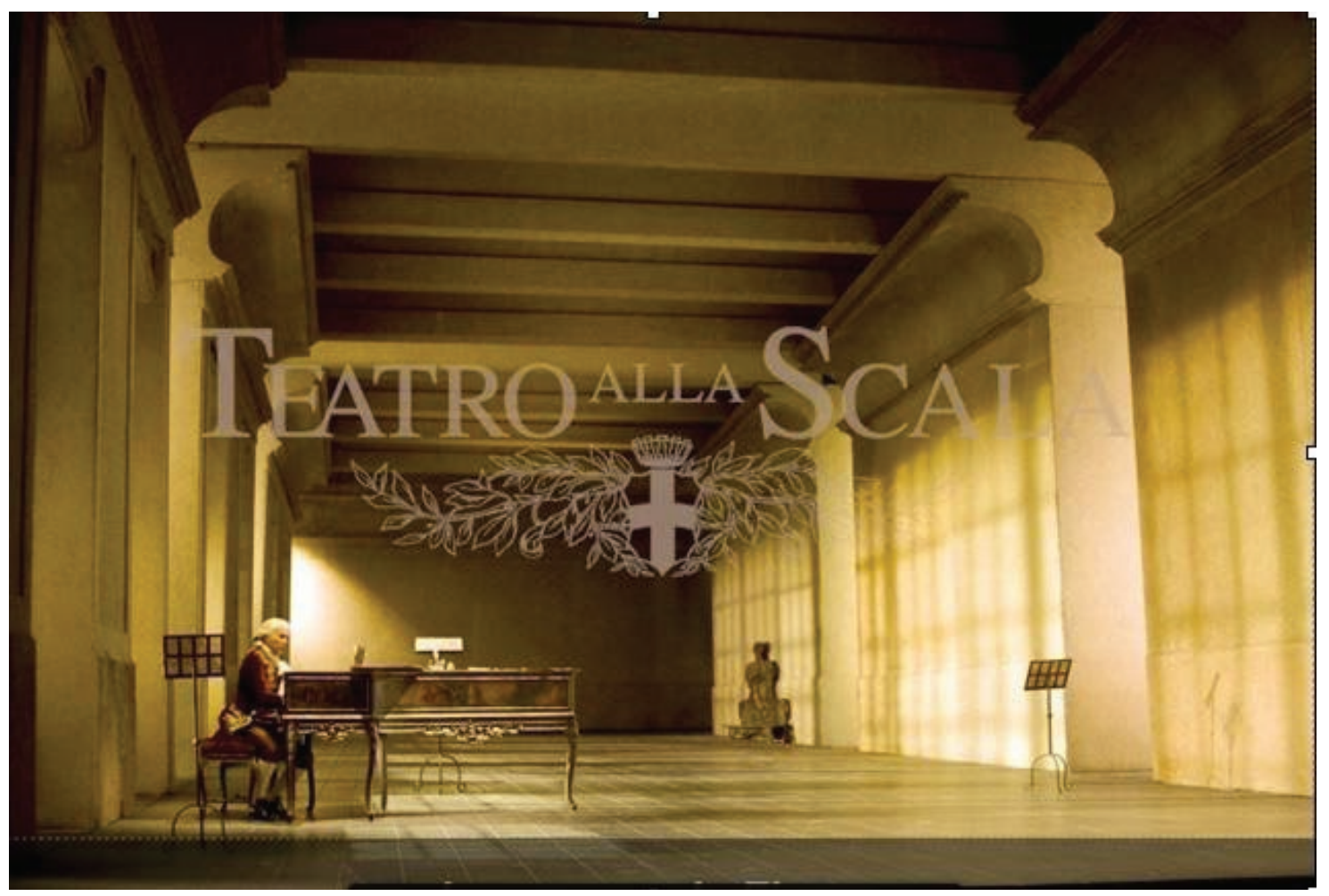

Les noces de Figaro [As Bodas de Fígaro], W. A. Mozart, direção de G. Strehler. Ato 3, foto de Marco Brescia, 1980. @ Teatro alla Scala. 2007.

Christophe Forey chega à conclusão de que "a luz é elemento vivo de um espetáculo, como o jogo dos atores ou dos cantores, ela não pode permanecer estática em seu primeiro gesto": evolui, por conseguinte, conforme os costumes da época. É fato sabido que a luz do cotidiano influenciou a modificação dos níveis de luminosidade dos espetáculos. O escuro tornou-se um luxo como a luz o era, inversa e historicamente, até o século XX. O espetáculo no século XX é a luz - ainda mais que o protocolo espetacular ritualiza o seu lançamento e o seu encerramento por uma passagem para a escuridão. Além disso, porém, numa história e num contexto cultural da onipotência da luz, qual é o lugar do escuro?

\section{... ao desconforto do escuro}

Por sua história técnica, o escuro pode ser percebido como o acidente. A extinção das chamas saindo dos bicos de gás é um risco muito grande no século XIX. Para além da ausência de luz, a emanação subsequente de gás tóxico invisível gera uma inquietude bem real. Com a eletricidade, as pessoas temem a pane e a dificuldade técnica em resolvê-la. É claro que tais riscos são atualmente obsoletos relativamente ao gás e são previstos e antecipados no que se refere à pane elétrica. Contudo, elas mantiveram nas mentes a associação do escuro com o temor do acidente e com a dificuldade em se mover na escuridão. Em seu tempo, os futuristas brincaram com esse medo, sobretudo num acontecimento cênico breve, Luce [Luz], de Francesco Cangiullo, em 1922. O princípio era roteirizado, deixando os espectadores no escuro 
em vez de iluminar o palco, como de hábito, depois de certo tempo, de acordo com o protocolo espetacular. $\bigcirc$ roteiro ${ }^{9}$ previa uma reação orquestrada que se amplificava por meio de vozes que reclamavam por luz:

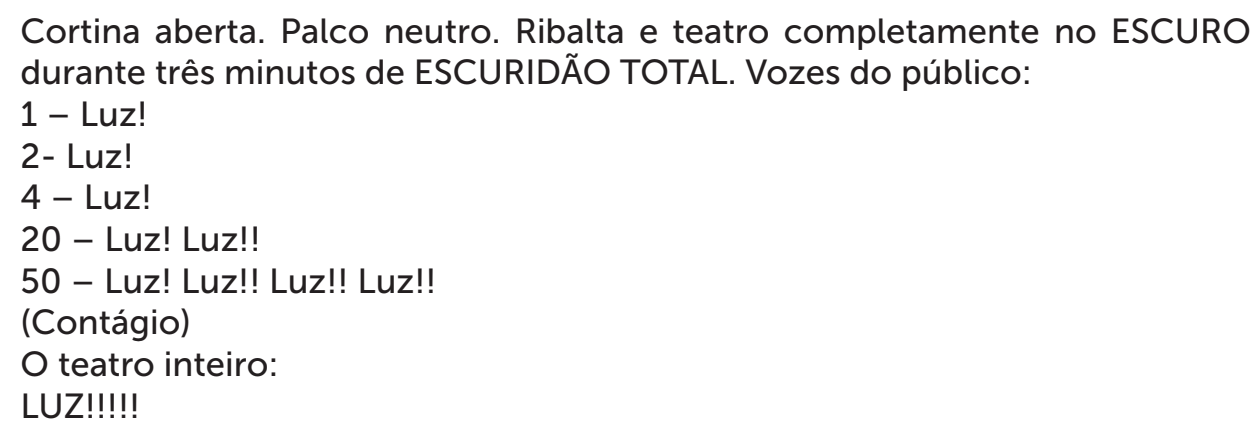

Estava previsto que esses apelos se transformassem numa crise "insensata". Depois, uma resposta não menos provocante consistia numa iluminação da ribalta e do teatro "EXAGERADAMENTE". Esse espetáculo futurista ilustra perfeitamente a situação que se torna não somente o seu impulso dramático até a exasperação, mas também mostra como o espectador é dela dependente: os espectadores esperam um controle da luz por parte dos artistas. No caso contrário, ou por jogo, a situação se transforma em drama, a tal ponto o escuro é percebido como um desconforto e uma negação das expectativas espetaculares. Esse poder pode se revelar cínico quando mergulhamos o espectador no escuro ou nele o mantemos sem nada lhe dar em troca.

Enquanto considerarmos a luz como o princípio de base, o escuro (exceto convenções protocolares admitidas) poderá ser percebido como uma violência. Ele pode ser percebido e vivido como ruptura brutal não somente porque teria sido produzido sem contemplação por um cut [corte], mas também porque encarnaria uma ruptura de confiança. Nossos modos de vida nos põem continuamente num ambiente luminoso. Apenas os protocolos espetaculares (cinema e espetáculo vivo) admitem o escuro. E ainda muito relativamente, já que os sinais luminosos de saída de emergência estão sempre lá para nos tranquilizar. O escuro não protocolar é potencialmente percebido como uma ação violenta e brutal - O que certos espetáculos utilizaram como recurso dramático (cênico) e dramatúrgico (significante).

É o caso de Salves [Salvas, Descargas], de Maguy Marin $(2012)^{10}$. É um espetáculo difícil de qualificar como coreográfico, se nos referirmos à tradição. Contudo, trata-se de um espetáculo baseado no movimento, sendo o blecaute o principal regulador. As situações começam a instalar-se, depois sistematicamente o seu impulso é minado por um blecaute brutal e preciso: uma mulher começa a colar os cacos de um vaso que se quebrou em contato com o chão, mas o seu gesto é interrompido por um blecaute. Ao espectador resta somente imaginar a sequência, ou seja, a recuperação completa da forma do vaso quebrado. Ora, o escuro rompe também o fluxo narrativo: o movimento de conjunto se constrói às avessas da continuidade. Quando

\footnotetext{
9 Ver: Giovani Lista. Futurisme. Manifestes — Documents - Proclamations. [Futurismo. Manifestos -Documentos - Proclamações]. Lausanne: L'Âge d'Homme, 1973.

${ }^{10}$ https://www.lightzoomlumiere.fr/realisation/salves-cie-maguy-marin-un-choc-visuel/
} 
uma sequência ulterior mostra a mesma mulher com o vaso pondo flores nele, já não sabemos se se trata de uma volta atrás (o vaso é o mesmo vaso de antes da sua queda?) ou de uma antecipação por salto elíptico. Constantemente detido na sequência das situações, o espectador é agredido por blecautes que contrariam o seu esforço mental de reconstrução. É um espetáculo que esgota literalmente o espectador. A escuridão vence o mental. Por meio de salvas, como seu titulo, o espetáculo dá e toma de volta. É a vitória do escuro sobre o espectador e sobre o dramático. Invisivelmente tecido pelos sete intérpretes na abertura, o fio condutor alude à "perda da experiência" denunciada por Walter Benjamin ${ }^{11}$. Segundo ele, a dificuldade de transmitir tanto as nossas experiências privadas quanto as da humanidade conduz a um empobrecimento que ameaça as gerações futuras e fragiliza o vínculo. O movimento da História se rompe e a continuidade se perde. Nesse espetáculo, de um blecaute a outro, junto com a História da Humanidade a história da arte se quebra: cai por terra a Estátua da Liberdade, ou a Vênus de Milo, como pontos de referência frágeis. Para o espectador, a perda de seus próprios parâmetros permite que experimente as catástrofes coletivas do século $\mathrm{XX}$, as quais transformaram o presente num campo de ruínas.

Embora anterior, o espetáculo N, de Angelin Preljocaj, criado em 2004, é, segundo as declarações do coreógrafo, um "título máscara", a tal ponto o que o espetáculo evoca e cuja experiência propicia são da ordem do inominável, do indizível: o sofrimento, a humilhação e a tortura impostos ao corpo tendem a aniquilá-lo. É o que N denuncia. Para esse objetivo engajado, Angelin Preljocaj, Ulf Langheinrich e Kurt Hentschläger, seus colaboradores, expuseram os corpos em cena àquela violência que se reveza com a infligida ao espectador, cujas faculdades sensoriais são abaladas $^{12}$. O som particularmente forte, essencialmente nos infrabaixos, associado a uma sequência muito longa com estroboscópios muito poderosos (o espetáculo era desaconselhado para os epilépticos e para as mulheres grávidas), cria um efeito de opressão e de agressão propício à denúncia. A aposta de um espetáculo como esse é mostrar e denunciar, ao mesmo tempo que faz sentir. As alternâncias de luz e de escuridão são instrumentalizadas de maneira consciente até o esgotamento. Encurralado, o espectador não tem escapatória: os infrabaixos ressoam no seu corpo como os jogos de luz agridem os seus olhos.

Nesses espetáculos não verbais, o visual adquire uma dimensão primordial. Embora em estado de choque repetido, o espectador avisado geralmente está apto a admitir essa nova convenção e a aderir a ela. Sofrimento e mal-estar são uma nova forma de empatia participativa para com a violência denunciada. No caso do teatro verbal, o contexto é totalmente outro. O suporte do visual para acompanhar o som é esperado, exceto quando se trata de uma gravação. O som da voz amplificado suporta o escuro, enquanto o texto dito por um ator em cena sem amplificação requer a ligação visual à sua fonte. O humano (o animal?) está habituado à alquimia da men-

\footnotetext{
11 Walter Benjamin. "Expérience et pauvreté" [Experiência e Pobreza], in OEuvres [Obras], t. 2. Tradução de Maurice de Gondillac, Painer Rochlitz e Pierre Rusch. Paris: Gallimard, 1972, 1974, 1977, 1978, 1985, 1989, 2000, p. 364-372.

12 https:/www.bing.com/videos/search?q=Angelin+Preljocaj++N\&pc=cosp\&ptag=G6C999N1234D010316A316A5D3C6E\&conlogo=CT3210127\&ru=\%2fsearch\%3fq\%3dAngelin\%2520Preljocaj\%2520\%2520N\%26pc\%3dcosp\%26ptag\%3dG6C999N1234D010316A316A5D3C6E\%26form\%3dCONBDF\%26conlogo\%3d CT3210127\&view=detail\&mmscn=vwrc\&mid=034B96F66B4D4C7021EC034B96F66B4D4C7021EC\&FORM=WRVORC
} 
sagem oral associada aos indicadores não verbais, ainda que esteja atualmente acostumado com as comunicações de todos os tipos com distâncias. Mas no protocolo do face a face que caracteriza justamente o espetáculo vivo, ele está nessa espera.

Nos anos de 1970-1980, o encenador André Engel era conhecido em seu trabalho com o iluminador André Diot por deixar o espectador incomodado, retirando-lhe o conforto da visibilidade da luz geral. Eles punham os espectadores em situação de fornecer um esforço para ver e ouvir e não somente consumir olhando e escutando. Não mergulhavam os espectadores no escuro, mas dosavam o nível tão baixo, em uníssono com as vozes dos atores, que o espectador era obrigado a se pôr numa tensão às vezes até à ruptura, saindo da sala. O Festival de Avignon - bem conhecido por suas cenas de provocação, tanto do lado dos artistas quanto do lado dos espectadores, que não hesitam em manifestar a sua desaprovação - foi o âmbito de tal atitude, durante a encenação feita por ele de Venise sauvée [Veneza Salva], de Hugo Von Hofmannsthal, em $1986^{13}$.

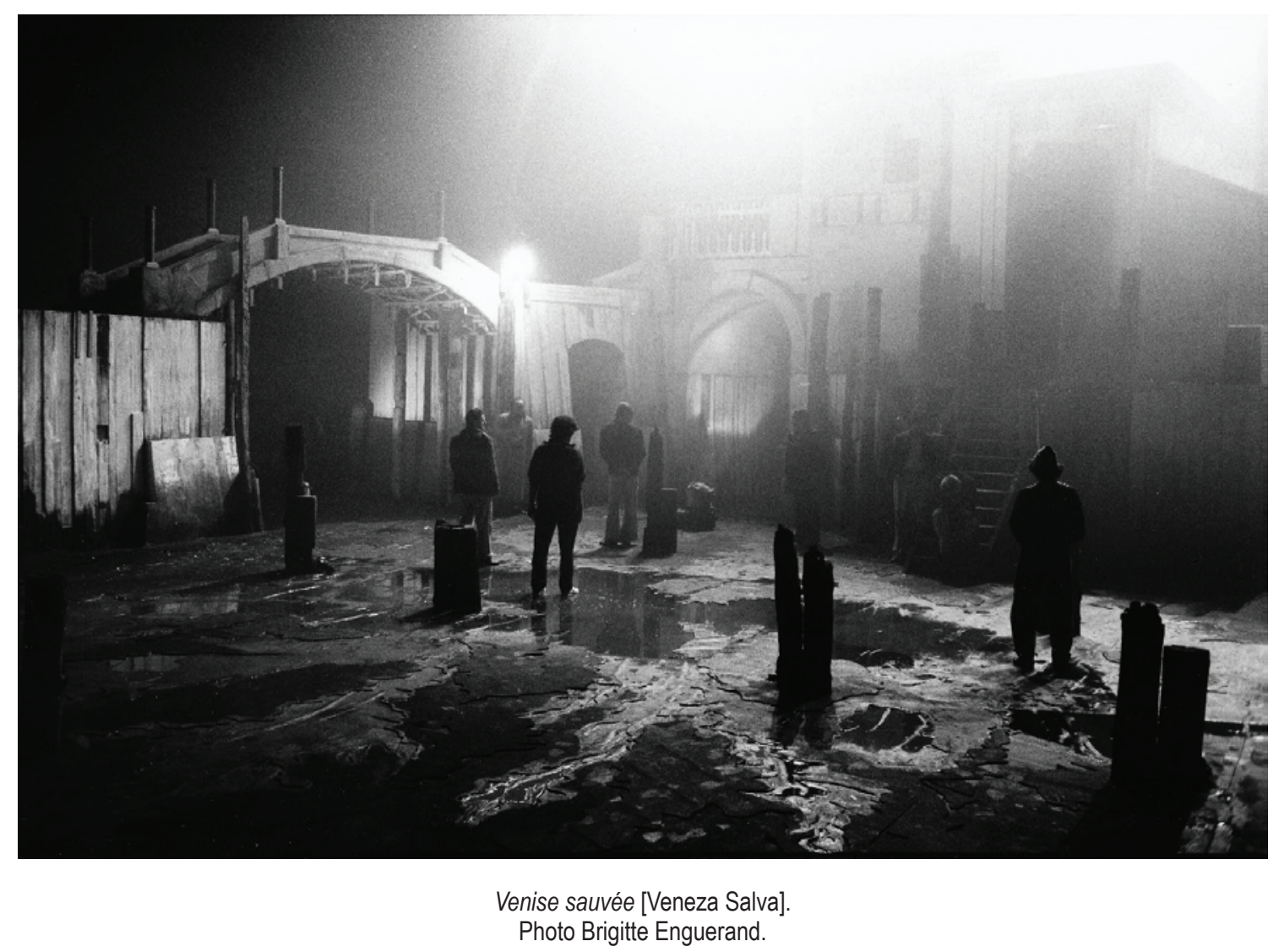

O cenário concebido por Nicky Rieti, de um realismo que se aparentava com o de um estúdio de filmagem, representava a Veneza da ralé, insalubre, mas que possuía ainda um pouco do seu esplendor passado. "Um poço de ar, sem luz, fedendo a peixe podre", diz a heroína. Tomando o texto ao pé da letra, a equipe artística a tornará uma realidade, transformando o lugar anônimo do ginásio do liceu Aubanel de

${ }^{13}$ Ver: Véronique Perruchon. André Engel. CEuvre théâtrale [André Engel. Obra Teatral]. Villeneuve d’Ascq: Presses universitaires du Septentrion, 2018. pp. 122-129. 
Avignon num porto, o de uma Veneza lacustre à noite, unicamente com a luz, pálida e parcial, de alguns lampadários. Longe da "verticalidade das chamas", evocada por Bachelard, a dos lampadários urbanos deitava por terra qualquer aspiração de escapar ao destino. Naquele cenário, o que contava para a equipe artística era criar a atmosfera de conspiração com um fundo de desespero amoroso. Assim, a noite foi tornada mais espessa por uma bruma permanente que escurecia ainda mais a cena, barrando o horizonte. A névoa associada a uma noite inquietante cobria toda a platéia com um véu espesso, numa atmosfera pesada. É claro: tratava-se de uma experiência polissensorial para o espectador, mas aquela atmosfera criava uma tensão dificilmente suportável, a tal ponto a escuridão em cena testemunhava um "apetite de irrepresentável"14, como Georges Banu então dizia. André Diot ${ }^{15}$ concebera uma iluminação não iluminante, inovando uma forma de estética cênica, apostando na capacidade retiniana do espectador para adaptar-se ao escuro. Longe da convenção, a noite realmente representada foi uma aposta ousada que não teve somente defensores, pois finalmente, nessa atitude provocante, a escuridão da noite e a luz não iluminante não tinham por finalidade apenas dar conta de uma realidade e de uma atmosfera de conspiração: havia revolta, para além da estética e da dramaturgia. Engel reivindicava pôr o espectador em estado de tensão. Tal ocorreu, e o espetáculo terminava com as vaias ou com os aplausos, se as pessoas estivessem sensíveis à estética e à coerência do conjunto, ou se se sentissem frustradas. Embora o espectador não fosse pessoalmente visado nessa tormenta, não obstante nela se perdia - pois o efeito da névoa, associado ao da noite, era acentuado por um tratamento sonoro desconcertante. Um texto geralmente inaudível, porque sussurrado, ainda que Anne Alvaro atuasse com as trincas da voz, tornando palpável o sofrimento da personagem. Foi demasiado pouco para tornar o texto inteligível. Venise sauvée [Veneza salva] era um espetáculo nada óbvio e demandava ser destrinchado.

No entanto, muito se falou da beleza daquele espetáculo afogado na bruma, elogiando-lhe as imagens. Se a chama enche de prazer o sonhador que a observa no escuro, como Bachelard, a noite escura sem a sombra de um clarão no horizonte desespera aquele que com ela se depara. Tal teatro repousa na adesão de defensores e não no conforto daquele que assiste a uma representação. É um teatro engajado para além daquilo que se espera do espectador.

Assim ocorreu com os tipos de espetáculo baseados na discordância das expectativas por uma experimentação da violência do escuro. Na escuridão, para que a experiência dê frutos e para que a mensagem se transmita, é necessária uma relação de confiança.

\footnotetext{
14 Georges Banu. Art Press nº 110 , janeiro de 1987.

15 André Diot, criador de luz nascido em 1935, foi sobretudo o colaborador no teatro e na ópera de André Engel e de Patrice Chéreau, durante mais de 40 anos. Oriundo do cinema, devemos a ele, na França, a contribuição dos projetores HMI para o teatro.
} 


\section{Do cativamento do escuro...}

O escuro se deixa cativar de um lado e de outro da ribalta quando a coerência dramatúrgica está presente. É preciso dedicar tempo e meios de se confrontar fisicamente com ele. Cabe aos criadores a responsabilidade de ver o escuro de um ponto de vista novo. Fora de uma solução insatisfatória ou do protocolo regulador, o escuro é um instrumento de construção dramática do espetáculo e uma componente da paleta de luz. A Magia Nova (corrente trazida pela Compagnie 14:20 [Companhia 14:20] ${ }^{16)}$ fez dele um uso dramático a serviço de uma construção dramatúrgica que implica o espectador. Obviamente, o escuro é um protocolo indispensável para os efeitos mágicos. No entanto, como instrumento dramático a serviço de uma dramaturgia, visa a fazer o espectador entrar num desequilíbrio dos sentidos que leva a um desvio do real. A magia repousa sempre no princípio de desestabilização do espectador. Aqui, a companhia visa à adesão a um real modificado. Isso passa por um acompanhamento dependente de uma mudança de hábitos e de uma desconstrução, para o espectador. Todavia, a mutação possui apenas a duração de um espetáculo para operar. Assim, o escuro sequencial desempenha um papel fundamental nesse acompanhamento, e, simultaneamente, possui uma função dramática e dramatúrgica. A alquimia dominada pela Compagnie 14:20 [Companhia 14:20] funciona particularmente bem em espetáculos como Vibrations [Vibrações] (2010, ou Wade in the water [Wade na água] (2016) ${ }^{17}$, que conta a história de um homem confrontado com os efeitos de um tumor no cérebro, que lhe fazem perder as suas referências, no sentido próprio e no figurado. O espectador vê o protagonista (Aragorn Boulanger), com gravidade zero, evoluir em câmara lenta ou ter o dom da ubiquidade. A austeridade do tema, os efeitos psicológicos da doença e as perturbações daí decorrentes com o seu círculo familiar são sentidos pelo espectador, ainda mais intensamente na medida em que ele está mergulhado numa atmosfera tenebrosa.

\footnotetext{
${ }^{16}$ La Magie nouvelle [A Magia Nova], corrente impulsionada e conduzida pela Cie de cirque 14:20 [Companhia de Circo 14:20], é uma marca criada por Raphaël Navarro, Clément Debailleul e Valentine Losseau, respectivamente mágico, circadiano e antropóloga, durante a criação da Companhia em 2000.

17 Wade in the water [Wade na água], criação: 2016; concepção e encenação: Clément Debailleul e Raphaël Navarro; coreografia: Aragorn Boulanger; luz: Elsa Revol. https://cie1420.jimdo.com/cr\%C3\%A9ation/spectacles/wade-in-the-water-1/
} 


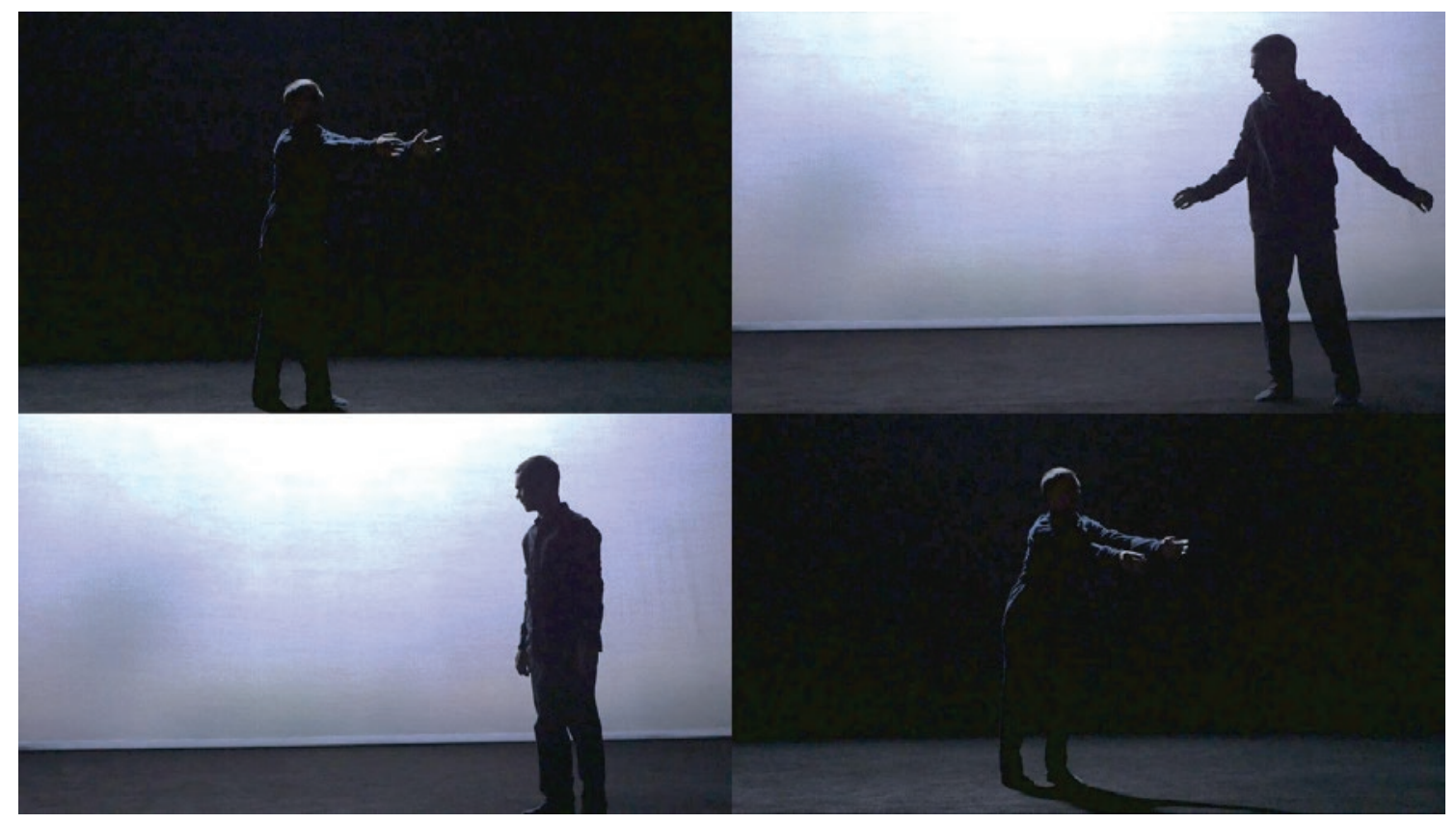

Wade in the water [Wade na água]. Crédito das fotos: Cie 14:20.

Os corpos em cena desafiam as leis da gravidade e da lógica. Eles pressionam a racionalidade com a sua presença e com a sua ausência, ou com o seu desdobramento num real recriado, ao qual o espectador se associa graças aos blecautes que ritmam o espetáculo. Integrado à dramaturgia e à poética cênica desde a sua gestação, o escuro não é percebido artificialmente como uma ruptura brutal que violentaria o protocolo em curso. O processo de encaminhamento do espectador é contido na própria dramaturgia do espetáculo. Em vez de meio, o escuro se transforma numa componente do espetáculo. Em Wade in the water [Wade na água], os blecautes instauram um ritmo que permite desarmar o ritmo do espetáculo. Ou seja, por um fenômeno de repetição, o espectador inscreve expectativas por ele conhecidas - fazemos blecaute para mudar o cenário, instalar uma elipse temporal, assinalar uma mudança de cena, etc. São as escuridões do real e do ritmo de um espetáculo. É racional. Mas aos poucos essa realidade é levada a desaparecer em proveito de outra, à qual o espectador chegou graças a esses patamares, sem se dar conta. Um universo em que os corpos flutuam, voam e perdem consistência. Realidade nova que, consequentemente, ele integra sem dificuldade. É jogando com as percepções do espectador, despertando o espírito para novas experiências sensoriais por associação, e modificando as referências culturais, cognitivas e sensoriais do espectador, que a magia se manifesta. 


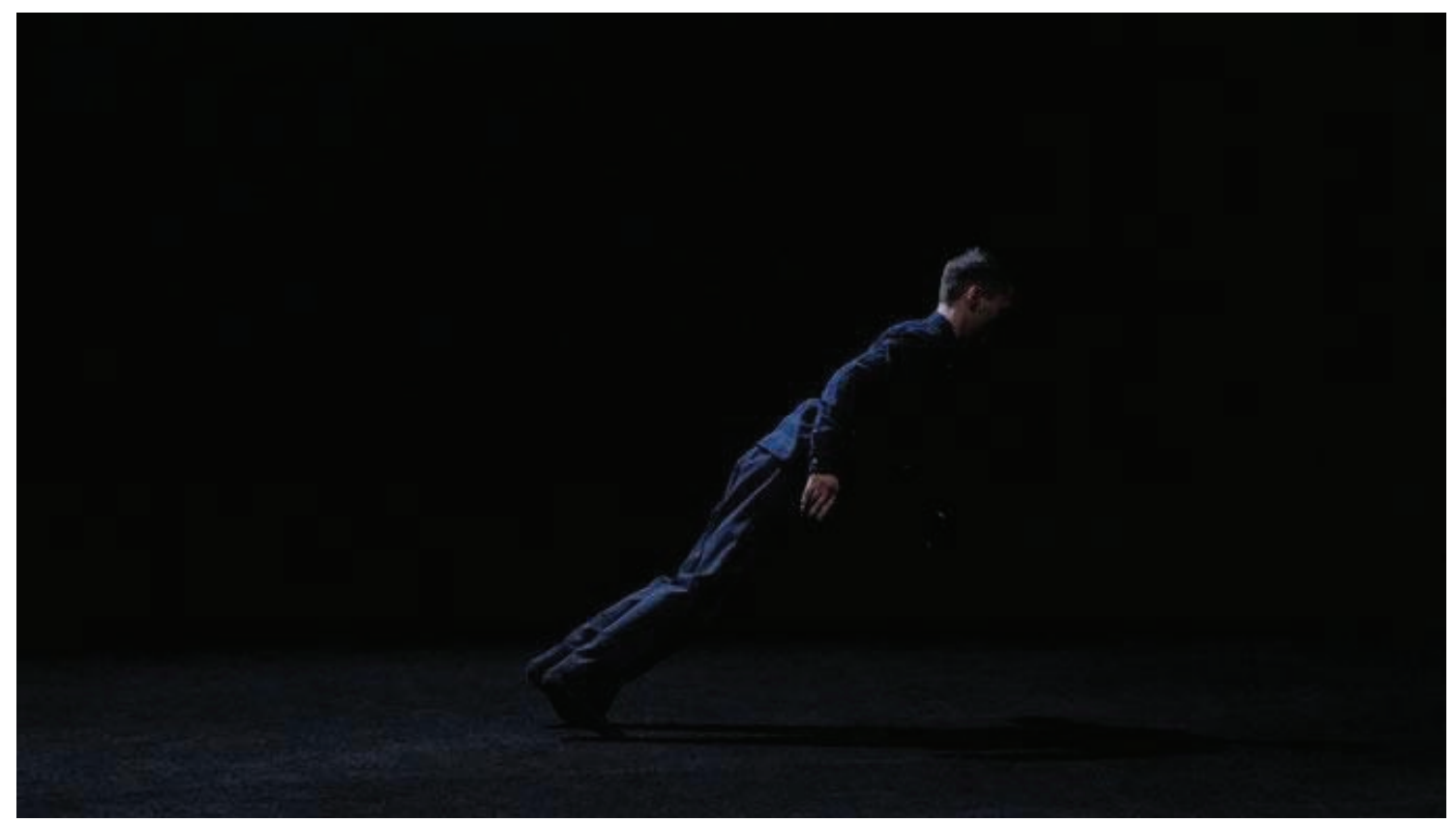

Wade in the water [Wade na água]. Crédito da foto: Cie 14:20.

Isso é verdade para o espectador que vai adotar o escuro como uma componente e para o criador que vai controlá-lo e cativar o espectador sem apavorá-lo, a fim de o conduzir para um real modificado. Mas como funciona para o performador?

Aragorn Boulanger, que trabalha com a luz de Elsa Revol, constrói a relação com o escuro particularmente em Ellipses [Elipses] (2012) ${ }^{18}$. Nesse espetáculo, Aragorn Boulanger declina a questão dos ritmos do corpo em interação com a luz e com os blecautes: o corpo é como que arrancado das leis da física, que são desestabilizadas num tempo e num espaço redesenhados pelas luzes de Elsa Revol, das quais o blecaute é uma componente. Concretamente, ele desenha um gesto cênico que é interrompido por um blecaute, gesto depois retomado quando a luz reacende, não onde o havíamos deixado, mas para onde foi levado pelo seu prolongamento no escuro. A personagem nos conduz ao limiar da realidade e do sonho, pois os seus gestos lentos, geralmente repetitivos, acabam por confundir as referências que o cérebro se dá, nessa reconstrução mental que, em resumo, lhe escapa. Ele parece buscar um gesto, um lugar no espaço da cena. Para que cada um dos seus gestos se torne a metáfora de uma derradeira travessia, Aragorn Boulanger trabalha com um estado de dissolução cuja experiência se imprime corporalmente, vinculada à luz ou ao escuro. Em Ellipses [Elipses], o acender, o apagar, a intensidade ou a direção da luz são pilotados no próprio decorrer da performance, que transfigura o espaço e oferece uma visão diferente, para o espectador, do gesto coreografado. Nesse estado o blecaute é tudo, menos um blecaute. Não é um obstáculo, mas permite, ao contrário, criar um espaço em que as referências reais e irreais são desfocadas ou até inúteis: apenas o

\footnotetext{
$18 \mathrm{https}: / /$ www.bing.com/videos/search?q=Ellipses+Aragorn+Boulanger\&pc=cosp\&ptag=G6C999N1234D010316A316A5D3C6E\&conlogo=CT3210127\&ru=\%2fsearch\%3fq\%3dEllipses\%2520Aragorn\%2520Boulanger\%26pc\%3dcosp\%26ptag\%3dG6C999N1234D010316A316A5D3C6E\%26form\%3dCONBDF\%26conlogo\%3dCT3210127\&view=detail\&mmscn=vwrc\&mid=18B66C52192F645B6B2B18B66C52192F645B6B2B\&FORM=WRVORC
} 
seu próprio corpo é uma referência para todo e qualquer movimento, deslocamento, desacelerações, acelerações. O blecaute induz uma mudança de ser que passa por uma exacerbação da propriocepção e traz aquela qualidade de relação corporal de si para si, experimentada por aqueles que atuam no escuro, embora possuam visão. Exatamente como a luz, o blecaute é, aqui, um suporte plástico e ambiental, mas também um meio de dar ao corpo desaparecido, mas adivinhado, um peso e uma dinâmica isentos da gravidade e da massa da sua corporeidade. O escuro participa da escrita própria às reconstituições cognitivas e ao trabalho do cérebro, entre visibilidade e invisibilidade, fenômenos de aparições e de desaparecimentos inesperados.

\section{... à comunhão profunda}

Magie nouvelle [Magia Nova] é um caso particularmente fecundo para repensar o vínculo com o escuro entre as componentes cênicas. Nessa forma espetacular, o pacto do espectador já não repousa no critério de conivência para com a garantia do efeito mágico (o que ocorre na magia tradicional), mas na aceitação do desvio do real. A Magie nouvelle [Magia Nova] instala progressivamente novas referências cognitivas, às quais o cérebro adere, aceitando que, neste mundo, os corpos flutuam, se movem em câmara lenta ou com extrema rapidez, desaparecem e reaparecem, se desdobram, etc. - processo no qual o escuro desempenha um papel sutil fundamental. Assim, no tempo de duração de um espetáculo, a adesão comum aos atores e aos espectadores em torno de uma realidade modificada ou desviada, portanto de uma nova realidade, depende daquela partilhada por toda e qualquer comunidade através da sua própria cultura ${ }^{19}$. A experiência da Magie nouvelle [Magia Nova] propicia a possibilidade de "sair da sua zona de conforto"20, segundo a expressão retomada pelos psicólogos do comportamento, se é que tal zona existe realmente. Nesse contexto singular, espectadores, criadores e intérpretes aprendem a pensar a cena com o escuro. Apoiando-se na prática e nas particularidades da Magie nouvelle [Magia Nova], que convidam a pressionar as referências, tratar-se-ia, graças ao escuro cênico, de experimentar a possibilidade de cortar os laços que nos aprisionam em uma representação dominada pelo medo e pela rejeição do escuro. Em suma: tratar-se-ia de se "desterritorializar" (Gilles Deleuze). O escuro articulado com a dramaturgia e com a dimensão dramática da cena nos espetáculos da Magie nouvelle [Magia Nova] supracitados nos oferece a oportunidade de repensar a sua presença cênica e, consequentemente, as suas funções e a sua eficácia para nos convidar a experimentar uma liberdade estético-política. Aderindo a um real modificado, fazemos tal experiência. Confrontando-nos com o escuro numa fusão ou até numa comunhão profunda, fazemos tal experiência.

Em suma, da dissonância do escuro bruto à concordância do escuro cativado, para além do concreto da cena e por meio dele, o caminho percorrido nos leva ao pensamento do mundo, pois continuar a suportar o escuro ou a aceitá-lo como uma

\footnotetext{
19 O que Valentine Losseau, antropóloga e dramaturga da Cie 14:20, estuda ao longo dos preconceitos cognitivos, https://artefake.fr/valentine-losseau/

${ }^{20}$ Expressão cuja origem reside nos estudos de R. Yerkes \& J. Dodson, "La Danse de la Souris, Une Étude du Comportement Animal" [A Dança do Camundongo, Um Estudo do Comportamento Animal], 1907.
} 
imposição do medo equivale a perpetuar um processo mortífero para a consciência humana e para a arte. O que nos leva a afirmar, à semelhança de Félix Guattari, que "a relação da subjetividade com a sua exterioridade - seja ela social, animal, vegetal, cósmica - se encontra assim comprometida numa espécie de movimento geral de implosão e de infantilização regressiva"21, devida a uma padronização cultural. No que tange à relação do sujeito (artista ou espectador) com o meio ambiente do espetáculo, quando o escuro cênico é mantido no seu papel brutal, isso equivale a uma infantilização do sujeito e à implosão do bom desenrolar do espetáculo (como na proposta provocante dos futuristas). A contrario, quando a violência do escuro é desviada a serviço de uma denúncia, como o mostram os espetáculos mencionados na primeira parte (Salves, $N$ ), então o escuro caminha no sentido de uma rediscussão do seu estatuto por amplificação. Persiste a pergunta que reside em saber se essas provas não representariam um risco de destruir a organização da subjetivação, proposta pelo próprio princípio do espetáculo vivo. Em suma, não há risco de ruptura, de vazamento, e, portanto, de retorno do medo subjacente, que destrói o equilíbrio e impõe a sua lei? É sutil a dosagem entre a ruptura e o dissensus consentido. Mas por uma dosagem e uma abordagem do escuro bem-feitas, é possível superar os princípios e os medos e mergulhar nas profundezas da escuridão e finalmente, como Baudelaire, “Plonger au fond du gouffre, Enfer ou Ciel, qu' importe? / Au fond de l'Inconnu pour trouver du nouveau!" [Mergulhar no fundo do abismo, Inferno ou Céu, que importa? / Rumo ao fundo do Desconhecido para encontrar algo novo!] ${ }^{22}$.

O escuro cativado e re-pensado possibilita uma abordagem filosófica do mundo percebido na sua inteireza, na qual os sujeitos não são nem isolados do ambiente, nem dominantes, numa superação do antropocentrismo - como na filosofia de Arne N/Ess, que propõe um pensamento do mundo segundo uma ecosofia entendida como filosofia de harmonia ou de equilíbrio entre as subjetividades, sejam elas quais forem. De fato, vimos na segunda parte que o escuro, por ser um dos temas que sofrem devido a um pensamento fechado, deve ser re-considerado, para tornar-se potencialmente uma componente forte de um pensamento holístico e ecosófico do espetáculo num mundo em mutação. Graças à experiência do escuro, à unificação e à perda das referências por ele propostas, esse pensamento da relação com o mundo pode adaptar-se ao universo do espetáculo.

Em síntese, e operando um deslizamento de um pensamento ecosófico do mundo para um pensamento do espetáculo vivo como micromundo, tal reflexão tem por objetivo propor o escuro como vetor potencial de subjetivação e de singularização para o espetáculo vivo. Ou seja: do "núcleo existencial parcial"23, que seria o espetáculo, para o âmago do mundo. O escuro no teatro pode participar da articulação ético-política - que Guatttari denomina também "ecosofia"24_ entre os três registros ecológicos: o ambiente, as relações sociais e a subjetividade humana. Nesse quadro

\footnotetext{
${ }^{21}$ Félix Guattari. Les trois écologies [As Três Ecologias]. Paris: Galilée, 1989. p. 12

${ }_{22}$ Na edição de 1861, o último capítulo de Les Fleurs du Mal [As Flores do Mal], intitulado "La mort" [A Morte], comporta seis poemas. "Le Voyage"[A Viagem] é o seu poema final e os versos citados são os dois últimos do poema, e, portanto, da coletânea.

${ }^{23}$ Félix Guattari. Op. cit., p. 37.

${ }^{24}$ Idem, p. 12
} 
de pensamento, o escuro já não é uma extração brutal e violenta do conforto da luz, mas um revelador da superação da supremacia do ser humano sobre o mundo. Como componente da luz no ambiente cênico, o escuro já não é apenas "maquínico" e técnico, mas também uma "componente de subjetivação"25. Cativado, torna-se parceiro da relação com o mundo encarnada pelo espetáculo. Longe da concepção debordiana, o espetáculo já não é objetivado, mas vivido numa articulação intersubjetiva sensível, no cerne de uma reflexão ético-política. Já não fugir do escuro nem o temer, já não o forçar a uma regulação protocolar e dominante do espetáculo, mas sim criar uma relação de confiança com um escuro cativado, compreendido, aprofundado, para uma nova arte da cena.

Assim, entendido como um ambiente poderosamente envolvente, o escuro, na suavidade de sua acolhida, pode acompanhar a comunhão profunda em que a arte cênica convida a viver. Da objetivação cênica à função profunda, ele convida à experiência derradeira da poesia, como sugere o poeta Junichirô Tanizaki, para quem o escuro "suscita ressonâncias indizíveis"26, que somente o corpo atento e a consciência desperta conseguirão detectar. Então, será superado o medo do escuro, fossilizado na sua representação. Conseguiremos encontrar a beleza da sua profundidade poética em ressonância com uma "ecologia profunda"27, que repousa numa indistinção metafísica entre os seres humanos e a natureza. O escuro cativado por meio de uma experiência da profundidade e do íntimo pode enveredar por um novo caminho de "rejeição da imagem do homem-no-ambiente em favor da imagem relacional do campo de vista total"28. Artistas, intérpretes, espectador, pesquisadores e pensadores, cabe a nós contar a sua nova história numa ecosofia da arte cênica a ser construída.

Recebido em: $17 / 03 / 2020$

Aprovado em: $17 / 03 / 2020$

\footnotetext{
25 Idem, p. 22.

${ }^{26}$ Junichirô Tanizaki. Éloge de l'ombre [Elogio da Sombra]. Tradução de René Sieffert. Paris: Verdier, 2011. p. 37.

27 Expressão de Arne N\&ESS, pioneiro da ecosofia, "deep ecology" é uma tese apresentada pela primeira vez em 1973, num artigo, "The Shallow and the Deep Long Range Ecology Movement”, traduzido em francês em H.-S. Afeissa (org.). Ethique de l'environnement. Nature, valeur, respect [Ética do meio ambiente. Natureza, valor, respeito]. Paris: Vrin, 2007.

${ }^{28}$ Arne Naess. "Le mouvement d'écologie superficielle et le mouvement d'écologie profonde de longue portée" [O movimento de ecologia superficial e 0 movimento de ecologia profunda de longo alcance], em N/ESS, Arne. Une écosophie pour la vie [Uma Ecosofia para a Vida]. Traduzido do norueguês por Naïd Mubalegh e do inglês por Pierre Madelin, sob a direção científica de Hicham-Stéphane Afeissa e Mathilde Ramadier. Paris: Seuil, 2017
} 